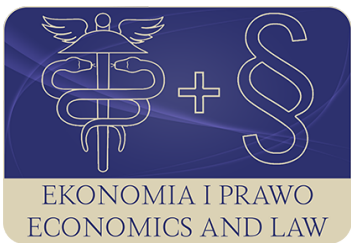

EKONOMIA I PRAWO. ECONOMICS AND LAW

Volume 19, Issue 3, September 2020

p-ISSN 1898-2255, e-ISSN 2392-1625

www.economicsandlaw.pl

ORIGINAL ARTICLE

received 13.07.2019; revised 17.02.2020; accepted 30.09.2020

Citation: Waligóra, A., Leszczyński, G., Zmyślony, P., \& Kot, M. (2020). Mapping the development of contextual knowledge in the area of the sharing economy. Ekonomia i Prawo. Economics and Law, 19(3): 551-568. doi:10.12775/EiP.2020.037.

\title{
Mapping the development of contextual knowledge in the area of the sharing economy
}

\section{ANNA WALIGÓRA}

corresponding author

Poznań University of Economics and Business, Institute of Socio-Economics, Department of Sociology and Business Ethics, al. Niepodleglosci 10, 61-875 Poznan, Poland

$\square$ anna.waligora@ue.poznan.pl

(D) orcid.org/0000-0003-1361-4709

\section{GRZEGORZ LESZCZYŃSKI}

Poznań University of Economics and Business, Institute of Marketing, Department of Marketing Strategies, Poland

$\square$ g.leszczynski@ue.poznan.pl

(D) orcid.org/0000-0003-2989-9729

\section{PIOTR ZMYŚLONY}

Poznań University of Economics and Business, Institute of International Business and Economics, Department of International Economics, Poland

曰.zmyslony@ue.poznan.pl

(D) orcid.org/0000-0002-1168-0254

\section{MATEUSZ KOT}

Poznań University of Economics and Business, Institute of Marketing, Department of Marketing

Strategies, Poland

$\square$ mateusz.kot@ue.poznan.pl

(D) orcid.org/0000-0001-8292-9961 


\begin{abstract}
Motivation: Contemporary economics provides to the practice of the social world functioning increasingly precise knowledge about how the modern economy and economics change. Although it seems that it is knowledge necessary to make science more useful for the social world, it creates a risk of blurring the general picture of the studied problems. One of the modern phenomena analysed in economic theory and tested in economic practice is the sharing economy (SE). Because it is a relatively new subject of economic analysis, it seems important to closely follow the development of academic work concerning SE (also on the basis of the knowledge provided by the social world).

Aim: The authors of the paper have focused on achieving the following research objectives: (1) identification of literature output in the area of SE, (2) assessment of cooperation between researchers dealing with SE topics and (3) diagnosis of thematic areas related to the studied phenomenon. The basis for the works on the research objectives was a set of 1411 papers related to SE, published in 2011-2018, in the Scopus database. For the research, quantitative analysis with elements of qualitative analysis was used.

Results: Based on the research conducted, the following conclusions were formulated: (1) the current literature on the SE phenomenon is fragmentary, (2) the cooperation, if any, between researchers dealing with SE is ephemeral, (3) SE contexts are focused on specific socio-economic phenomena.
\end{abstract}

Keywords: sharing economy; circular economy; collaborative economy; gig economy; platform economy; co-occurrence analysis

JEL: Al2; Al3; Al4; C55; D16; L84; O14

\title{
1. Introduction
}

The theory of economics, both due to the constantly accelerating globalisation processes (Mir et al., 2014, pp. 613-614) and the local-context-related requirements that are formulated towards it (e.g. relating to the development of the concept of sustainable development and corporate social responsibility), is particularly important for the practice of the functioning of the social world and managing it (Ferriss, 2004; Frenken \& Schor, 2017; Zelizer, 2010).

One of the issues that require taking up the responsibility for describing economic phenomena accordingly is the sharing economy (Belk, 2014), which, practiced in various areas of the social world, seems to be insufficiently described in the theory of science. This carries two consequences: (1) SE is not diagnosed in science as a socio-economic phenomenon, and sufficient knowledge for its macroeconomic description and prediction of development trends in this area is not delivered; (2) a multi-dimensional (e.g. social, economic, technological, etc.) description of the phenomenon that would explain its dynamics is not built in a comprehensible and coherent way. The above assumptions have prompted the authors of the paper to focus on achieving the following research objectives: (1) identification of literature output in the field of SE, (2) assessment of cooperation between researchers dealing with SE topics and (3) diagnosis of thematic areas related to the studied phenomenon. 
This paper starts with a literature review that presents a short history of how the concepts of the sharing economy, circular economy, collaborative economy, gig economy and platform economy are understood in academic literature. It is shown that the published academic materials are of fragmentary nature, and the review papers showing the complexity of the SE phenomenon are few and most often concern the topic of designing research on the phenomenon in individual research institutions. The research method applied in this paper is based on quantitative analysis, with elements of qualitative analysis, of the co-occurrence of keywords used in research papers published in the field of social science over the past seven years, that is from the moment when the keyword 'sharing economy' appeared in the academic databases collected in Scopus (2019). The analysis was carried out on the basis of 1411 articles regarding SE, published in 2011-2018 in the Scopus (2019) database. The results provide examples of analysis of the concept of the sharing economy combined with keywords such as: 'circular economy', 'collaborative economy', 'gig economy' and 'platform economy'. The discussion presents the consequences of the adopted methodological approach and the possibilities of developing and applying a theoretical approach in the study of SE and the practice of the economy. The conclusions present proposals for micro-, meso-, and macroeconomic implications of mapping the development of contextual knowledge in the area of the sharing economy. Our conclusions refer to: fragmentation of the current literature on the SE phenomenon, ephemeral cooperation between researchers dealing with SE, and focus of the SE literature on specific socio-economic phenomena. In further research proposals, emphasis is placed on the need for mixed research (in the field of disciplines of science, research methodology and practical review) in the area of SE.

\section{Literature review}

In the literature on the subject, no consensus has been reached on how to define the sharing economy concept and related terms. Firstly, attempts to reach an agreement on this matter are few in number and do not really lead to any binding solutions. Secondly, the practical and theoretical scope of SE is difficult to determine (Cherry \& Pidgeon, 2018, p. 970; Hamari et al., 2016; Lamberton \& Rose, 2012).

Codagnone \& Martens (2016, p. 5) point to the 'conceptual and empirical fog' resulting from the short existence of the sharing economy in its contemporary shape, both in the theory of science and in the practice of the economy. This argument combines the problem of penetrating the 'world' of academic literature and popular science literature. Cheng (2016, p. 69) draws attention to 'grey literature', a phenomenon in which organisations operating outside the traditionally understood academic world and outside the circulation of science publishing concentrate publications concerning the analysed concepts. 
Sutherland \& Jarrahi (2018, pp. 229-230) define SE from the angle of the socio-economic factors that affect this phenomenon: 'SE is the culmination of a large number of economic, technological, societal, political, and environmental trends, perspectives on it widely vary'. This approach to the subject of SE means that a valid definition will probably not arise.

The popularity of the sharing economy topic is also associated with the successors of this new economic trend (Martin et al., 2017, p. 2; Nadler, 2014), i.e. platforms such as Airbnb and Uber (Cohen \& Kietzmann, 2014), which makes the focal point of the sharing economy to be platform solutions, omitting other SE-related issues which are developing in parallel in this area.

To summarise, the authors raise various arguments (from general, mainly social, to the most detailed, mainly economic, ones) trying to explain the reasons for this state of knowledge. Contextual knowledge regarding the sharing economy, but also concepts such as circular economy, collaborative economy, gig economy, or platform economy, is dispersed and does not present a coherent picture of the knowledge in this field. Thus, the added value of this paper is derived from a new perspective it opens on the sharing economy and co-occurring concepts, setting them all in relation to the theory of science and the practice of the functioning of the social world. Given the current level of development of academic discussion in the field of SE, it seems that the cognitive value of SE has not been studied before in the way proposed in this paper.

\section{Methods}

The methodology underlying the conducted research is based on a simple, but seemingly indispensable for science, assumption that to understand socio-economic phenomena that are extensive and have significance for the contemporary world, which SE undoubtedly is part of, it is necessary to approach the undertaken research problem as comprehensively as possible. In the case of the research on SE, this task is difficult because the concept does not have a coherent, established definition, and it seems that such a definition is still in statu nascendi, in insufficiently recognised, numerous and often unrelated contexts. By contexts, we understand other fields of science and knowledge defined at the level of the keywords with which SE co-exists in academic literature.

To study the aforementioned thesis, a systematic mapping review was performed. The research methods followed the mapping literature review using the SALSA framework (see Grant \& Booth, 2009). This framework consists of the following steps: searching for relevant publications, appraisal of the collected writings for their quality, synthesis of the created database into the form of maps, and analysis in order to summarise the best of what remains to capture the essence of the science perspective of SE (Grant \& Booth, 2009).

The search phase was conducted in May 2019. We used one of the most popular and widely recognised scientific writing databases - Scopus (2019). We searched for articles that refer to the concept of the sharing economy, thus 
the research phrase was simply 'sharing economy'. As the result, we gathered a basis of 1411 papers related to SE from the timeframe of 2011-2018 and from the disciplines of social science in which the concept of the sharing economy appeared. The reasons for choosing such disciplines are following. Economics is the basic discipline of the research undertaken. Sociology, on the other hand, is an indispensable theoretical-practical context of the sharing economy, and therefore texts published in this field were also taken into account in the analysis.

The synthesis part of the literature review used the VOSviewer analytical software (van Eck \& Waltman, 2009). We used this tool to map the papers which regarded the sharing economy concept and the accompanying concepts (or concepts that are accompanied by SE). More precisely, we used co-citation analysis, as it is regarded as a valid method of studying the intellectual structure of a discipline of science. Two assumptions are important for that approach: (1) documents frequently cited together are more likely to influence the discipline than those less cited, (2) papers cited frequently in a pair are more likely to have similar or related concepts (Zupic \& Cater, 2015).

The analysis was aimed at identifying the development of contextual knowledge in the area of the sharing economy, which brings us closer to understanding what SE is for modern science. Initially, a set of all concepts combined by authors writing about SE at the keyword level was analysed. Then, from such a set of concepts, contextual concepts directly relating to the discipline of economics were selected.

The choice of the concepts for the contextual analysis was arbitrary (qualitative), and was based on the assumption that they should contain the phrase 'economy', for several reasons. First of all, this paper concerns the discipline of economics; secondly, adjectival terms coinciding with the concept of the economy seem to contain the promise of 'science', the definition of which is one of the ambitions of this paper; thirdly, the concepts selected for the contextual analysis have a definitional outline, which makes it possible to presume that they contribute to recognising and describing the concept of SE in the theory of science.

The strengths of the applied research methodology include the analysis of all texts containing the key concept of SE in keywords which have been published in one of the most important databases for modern science. Consideration should be given to extending further quantitative analyses to texts not included in this platform and expanding the research into the main body of the aggregated papers, provided that the discussion in this paper contributes to the emergence of a new quality of understanding of scientific cognition.

\section{Results}

The research presented in this paper was divided into two main stages. The first of these focused on examining the coexistence of the concept of SE with 
other keywords selected by the authors of the analysed articles (schemes 1-2). In the second stage, the analysis focused on which keywords in the papers extracted from the Scopus (2019) database containing the word 'economy' coincide with the concept of SE (schemes 3-6).

Scheme 1 presents the widest view of the research problem undertaken. Scheme 1 shows the maximum number of keywords that appeared in the research literature in the Scopus (2019) database at least once with the concept of the sharing economy. The scheme 1 creates, in a sense, a set of concentric circles, the widest of which is a set of concepts that in keywords have been combined with the concept of SE once. Concepts close to the central part of the scheme 1 represent multiple coexistence of the sharing economy concept with another selected key phrase. The larger letters the word or keyword has, the more often it coexists with SE. The shades of grey in scheme 1 are an automated proposal of the analytical programme for combining individual concepts into thematic clusters, as discussed in detail in schemes 3-6.

As can be seen in scheme 1, concepts focused around SE resulting from the analysis based on the assumption of at least one coincidence do not create a clear thematic or problematic set. This collection could be most widely defined by a combination of contemporary socio-economic problems, which are partly reflected in the practice of economics (e.g. benefit of carpooling service, car insurance, charging station), partly in economic theory (e.g. big data, agency theory, alternative finance), and partly in other subdisciplines of the theory and practice of social sciences (e.g. migrants, local level, behaviour). We can also observe existence of two brands, Uber and Airbnb, that pop up in many papers dealing with SE.

Scheme 2 presents a more specific arrangement of co-occurrences of concepts in which only such key entries are included which coincided with the concept of SE at least three times in the academic literature of the Scopus (2019) database in 2011-2018. The comparison shows that the concepts, as in scheme 1 , refer to different fields of science and the social world. In contrast to the first set, however, they create specific, thematically related, conceptual systems expressed by means of networks and colours that identify individual areas of knowledge.

The creation of scheme 2 involved a risk arising from the machine selection of the concepts that were to be combined into clusters and the quality of the key entries entered into the Scopus (2019) database. However, it can be stated that the generated scheme 2 allowed for outlining conceptual areas relating to SE, such as: tourism, economy platforms, collaborative consumption, transportation, sustainability and others, which indicate the fragmentation and dispersion of research on the sharing economy issues.

Schemes 3-6 present the concepts chosen by the authors from the machine combination - keywords containing the concept of 'economy' which seem to contain the most valuable, from the perspective of the objectives of this study, information on SE relationship with the economic and social knowledge. 
In the analysed literature sources, the concepts of the sharing economy and circular economy were compared with such keywords as: "collaborative consumption', 'sustainable mobility', 'smart city', 'sustainable development', 'millennial' and 'cities'. It is difficult to include the matters represented by these keywords in the field of a particular discipline of science or make a separation between market practices, technology and social problems. What the mentioned areas of the theory and practice of science have in common is that they relate to the currently diagnosed determinants of the future of socio-economic matters.

It seems that the resulting set refers to the issues of how the modern city functions, with an emphasis on the sustainable exchange of goods and services embedded in the problem of sustainable development.

Studies on the concepts of the sharing economy and collaborative economy have shown connections between concepts such as collaborative consumption, Uber, sustainability transitions, peer-to-peer accommodation, discrimination, platforms, crowdfunding, housing, platform capitalism, commons, tourism, gentrification and sustainability. As in the case of analyses regarding the co-occurrence of SE and circular economy, it is difficult to show a clear inclination towards a specific set of knowledge. Contrary to the above analysis, it seems that the sharing economy and collaborative economy are more often analysed in the context of economic and social problems of the microscale, more focused on the community. There are also more combinations of keywords resulting from the sharing economy and collaborative economy.

Gig economy is the most detailed of the terms combined with SE in the literature analysis. It refers to the conditions of the modern labour market. It may be treated as a consequence of the appearance of SE. It is also probably the biggest 'mental shortcut' when it comes to semantics. Gig economy refers most strongly to the indirect functioning of SE via virtual market exchange intermediaries, which are called 'platforms' in various sets of keywords. This is typical of the contemporary writing on the issue of the sharing economy.

$\mathrm{SE}$ and gig economy were analysed in conjunction with such concepts as collaborative consumption, Uber, digital platforms, employment, internet, platform capitalism, platform economy and diverse economies. It seems that this combination provided a fuzzy and the least precise combination of the keyword bundles analysed.

Platform economy seems to be the concept combined with SE which is best recognised in the literature as well as most technical. In the analyses carried out, the concepts of the sharing economy and platform economy were compared with such keywords as: 'collaborative consumption', 'internet', 'digital platforms', 'gig economy', 'diverse economies', 'work' and 'tourism'. The concepts of the sharing economy and platform economy are similar to the ones presented in scheme 6. Platform economics is clearly emerging as a new subdiscipline of knowledge combined with dynamic technological development and globalisation processes that facilitate the implementation of new technologies (e.g. 
through the unification of the spoken language, and consequently the unification of the platform language).

It seems that SE and platform economy comparison illustrates the tendency to combine these terms in the literature. The list of keywords attributed in the literature to this set gives legible and thematically consistent data sets.

\section{Discussion}

The visualisation of bibliometric networks presented above reflects the state of knowledge on SE based on the number of publications and links between them. The 'conceptual mess' created as a result of the rapid evolution illustrates the complexity and multidimensionality of the SE phenomenon, and the attempts to 'arrange' them presented in the text only show the economic and social approach to the problem. The entire knowledge about SE that we currently have is fragmentary and dispersed. Perhaps this testifies to the actual significance of the SE phenomenon, and perhaps less than a decade of analysing this dynamically developing practical-theoretical problem is not enough to formulate valuable conclusions for the theory of science. The presented clusters show the main areas of co-occurrence of the concept of SE with keywords the importance of which in science is constantly examined. The proposed configuration of the concepts is therefore unique, because it shows potential developments of the academic knowledge in the studied area, while its cognitive value understood as providing data for describing, solving and predicting social problems is uncertain.

The arbitrary selection of the concepts presented in the paper lies with the authors and is one of many possible proposals for the analysis of the research problem that has been undertaken. Previous analyses of co-citations were focused on selected terms referring to sub-disciplines of economics (Cheng, 2016, pp. 60-61; Sainaghi et al., 2019) or referred to a narrower conceptual scope (Sutherland \& Jarrahi, 2018, pp. 3-4). This paper is therefore a new look at the keyword co-occurrence approach regarding the concept of SE in socio-economic terms.

From the perspective of the objectives of this study, it seems important to present yet another conclusion, though it does not directly relate to the very subject of the paper, on how academicians select keywords in their studies. In future considerations based on the co-occurrence approach, it is worth recreating the strategies and the logic behind how these concepts are matched.

\section{Conclusions}

The analytical findings on mapping the development of contextual knowledge in the sharing economy presented above allow for several conclusions. First of all, the conceptual order focused on the sharing economy and the keywords analysed is composed of diverse sets of concepts referring to various disciplines 
of social sciences, advanced technological issues and social aspects. A further modelling in the above-described scope would probably lead to an increase in the diversity of keywords. From the time of the research until the publication of this paper, the proportions in the frequency relations of the terms used may have changed and showed other relationships. This observation is important because, in order to understand the nature of SE, this phenomenon should be placed in a system of dynamically changing data and embedded in a specific social context.

Secondly, the most often mentioned keywords combined with the sharing economy and circular economy, collaborative economy, gig economy and platform economy are collaborative consumption and platforms (or digital platforms), indicating the possible areas of further research. Both the concept of collaborative consumption and platforms (or digital platforms) have evolved owing to the development of SE. They are also a 'litmus test' of the effects of the sharing economy. Against the background of emerging sets of conceptual links, they seem quite promising in analyses due to their fairly clear designations.

Thirdly, the keywords around the analysed concepts are not directly related to the contemporary understanding of the sharing economy. These are, e.g.: discrimination, gentrification, diverse economies, millennials and employment, and they are supposed to be related to the subject of social policy. They deserve further analytical attention and perhaps should be considered separately because of their importance for the functioning of the social world.

Finally, from in-depth qualitative analyses based on processed knowledge, the analysis shows that it is difficult to identify research institutions (embedded in time or space for a long time) dealing with this problem. The concept of the sharing economy, contrary to the assumptions made in this paper, is used more as a concept accompanying the dominant issues discussed in a paper, which makes it difficult to actually construct the theoretical framework for $\mathrm{SE}$ at this stage of the development of academic knowledge. Perhaps the role of SE at the present stage of knowledge development is to stimulate considerations regarding more advanced and more widely described issues undertaken by modern science.

Conclusions of this paper are limited by the shortcomings of the applied research method, i.e. the bibliometric network visualisations. As its main idea is to allow large amounts of complex bibliographic data to be analysed in a relatively easy way, it usually implies a loss of information (van Eck \& Waltman, 2014, p. 28). This takes place because the arbitrary selection of the concepts presented in the paper lies with the authors and is one of many possible proposals for the analysis of the research problem that has been undertaken. This analysis is based on the keywords selected by the authors of the analysed papers, which may be misleading. Because of these issues, the results of our study should be considered as a complement rather than a substitute to expert judgment. 


\section{Further research proposals}

Proposals for future analysis are related to the ongoing evolution caused by the emergence of SE. Theoretical reflection is parallel to the socio-economic phenomena caused by SE. In turn, SE may not be seen as belonging strictly to a single discipline of science, nor does it fit well into the distinction among economic, social, technical and other processes accompanying the studied phenomenon. This determines the need for conducting mixed (quantitative and qualitative) research in order to capture multi-dimensional processes.

The concept of the sharing economy functions in a specific socio-economic context, which makes it even more interesting for further analysis. Each of the keywords the co-occurrence of which with SE was analysed in the paper (circular economy, collaborative economy, gig economy, platform economy) carries the promise of formulating answers (in practice, in the social world: solutions) for the problems challenging the modern world. If they are only one of possible alternatives (visible in the analysis presented in this text), the question remains where to look for other co-occurring fragments of knowledge. The conducted research also shows that the theoretical configurations in which SE occurs overlap, which indicates the need for dialogue between experts from various fields, both science and the social world, in order to further the research, and above all predict what can bring about a rapid development of SE in the future.

For the above-mentioned reasons, multidisciplinary literature studies and analogous cooperation of theoreticians, researchers and practitioners, as well as continuous reference of SE to other socio-economic issues seem to be a good direction to follow in research work related to SE.

\section{References}

Belk, R. (2014). You are what you can access: sharing and collaborative consumption online. Journal of Business Research, 67(8). doi:10.1016/j. jbusres.2013.10.001.

Cheng, M. (2016). Sharing economy: a review and agenda for future research. International Journal of Hospitality Management, 57. doi:10.1016/j. ijhm.2016.06.003.

Cherry, C.E., \& Pidgeon, N.F. (2018). Is sharing the solution: exploring public acceptability of the sharing economy. Journal of Cleaner Production, 195. doi:10.1016/j.jclepro.2018.05.278.

Codagnone, C., \& Martens, B. (2016). Scoping the sharing economy: origins, definitions, impact and regulatory issues. Institute for Prospective Technological Studies Digital Economy Working Paper, 2016/01.

Cohen, B., \& Kietzmann, J. (2014). Ride on: mobility business models for the sharing economy. Organization \& Environment, 27(3). doi:10.1177/1086026614546199. 
Ferriss, A.L. (2004). The quality of life concept in sociology. The American Sociologist, 35(3). doi:10.1007/s12108-004-1016-3.

Frenken, K., \& Schor, J. (2017). Putting the sharing economy into perspective. Environmental Innovation and Societal Transitions, 23. doi:10.1016/j. eist.2017.01.003.

Grant, M.J., \& Booth, A. (2009). A typology of reviews: an analysis of 14 review types and associated methodologies. Health Information and Libraries Journal, 26(2). doi:10.1111/j.1471-1842.2009.00848.x.

Hamari, J., Sjöklint, M., \& Ukkonen, A. (2016). The sharing economy: why people participate in collaborative consumption. Journal of the Association for Information Science and Technology, 67(9). doi:10.1002/asi.23552.

Lamberton, C.P., \& Rose, R.L. (2012). When is ours better than mine: a framework for understanding and altering participation in commercial sharing systems. Journal of Marketing, 76(4). doi:10.1509/jm.10.0368.

Martin, C.J., Upham, P., \& Klapper, R. (2017). Democratising platform governance in the sharing economy: an analytical framework and initial empirical insights. Journal of Cleaner Production, 166. doi:10.1016/j.jclepro.2017.08.123.

Mir, U.R., Hassan, S.M., \& Qadri, M.M. (2014). Understanding globalization and its future: an analysis. Pakistan Journal of Social Sciences, 34(2).

Nadler, S. (2014). The sharing economy: what is it and where is it going. Unpublished M.B.A. thesis, Sloan School of Management.

Sainaghi, R., Köseoglu, M.A., d’ Angella, F., \& Mehraliyev, F. (2019). Sharing economy: a co-citation analysis. Current Issues in Tourism. Advance online publication. doi:10.1080/13683500.2019.1588233.

Scopus. (2019). Retrieved 05.05.2019 from https://www.scopus.com.

Sutherland, W., \& Jarrahi, M.H. (2018) The sharing economy and digital platforms: a review and research agenda. International Journal of Information Management, 43. doi:10.1016/j.ijinfomgt.2018.07.004.

van Eck, N.J., \& Waltman, L. (2009). Software survey: VOSviewer, a computer program for bibliometric mapping. Scientometrics, 84(2). doi:10.1007/ sl1192-009-0146-3.

van Eck, N.J., Waltman, L. (2014), Visualizing bibliometric networks. In Y. Ding, R. Rousseau, \& D. Wolfram (Eds.), Measuring scholarly impact: methods and practice. Cham: Springer. doi:10.1007/978-3-319-10377-8_13.

Zelizer, V.A. (2010). Economic lives: how culture shapes the economy. Princeton: Princeton University Press.

Zupic, I., \& Cater, T. (2015). Bibliometric methods in management and organization. Organizational Research Methods, 18(3). doi:10.1177/1094428114562629. 


\section{Acknowledgements}

Author contributions: authors have given an approval to the final version of the article. Authors contributed to this work as follows: A.W. developed the concept and designed the study, M.K. collected the data, A.W. and M.K. analysed and interpreted the data, A.W., G.L. and P.Z. prepared draft of article, G.L. and P.Z. revised the article critically for important intellectual content.

Funding: this research was undertaken as part of the Evolution of inter-organizational relationships as a result of the sharing economy: micro-, meso-, and macroeconomic implications project and was fully funded by the Poznan University of Economics and Business.

Note: the results of this study were presented at 8th International Scientific Conference: Contemporary Economic Problems 'Social-economic problems in the era of globalization: theory and practice' (May, 22, 2019, Torun, Poland). 


\section{Appendix}

Scheme 1 .

Keywords co-occurrence (at least single co-occurrence)

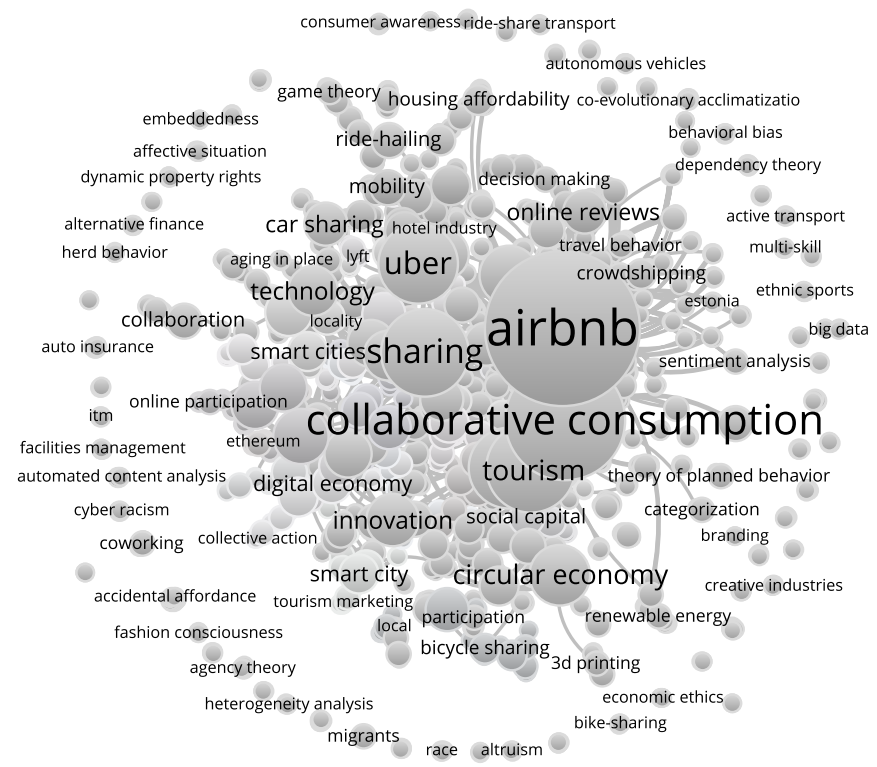

Source: Own preparation based on Scopus (2019). 
Scheme 2.

Keywords co-occurrence (at least triple co-occurrence)

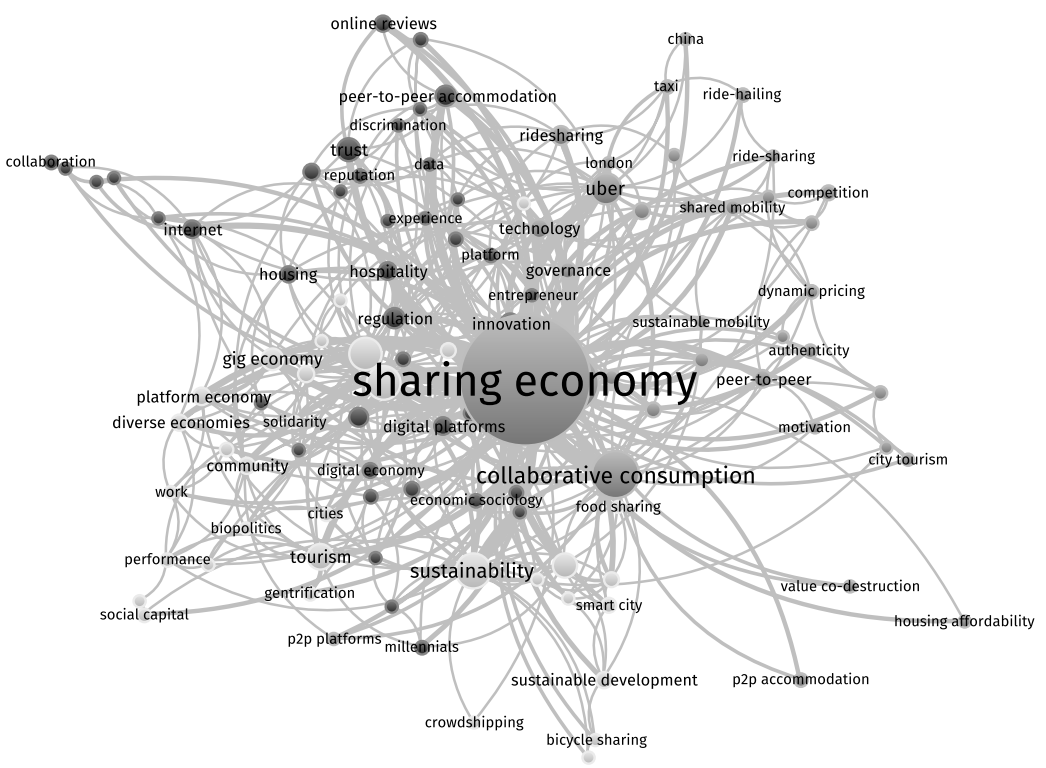

Source: Own preparation based on Scopus (2019). 
Scheme 3.

Sharing economy and circular economy co-occurrence

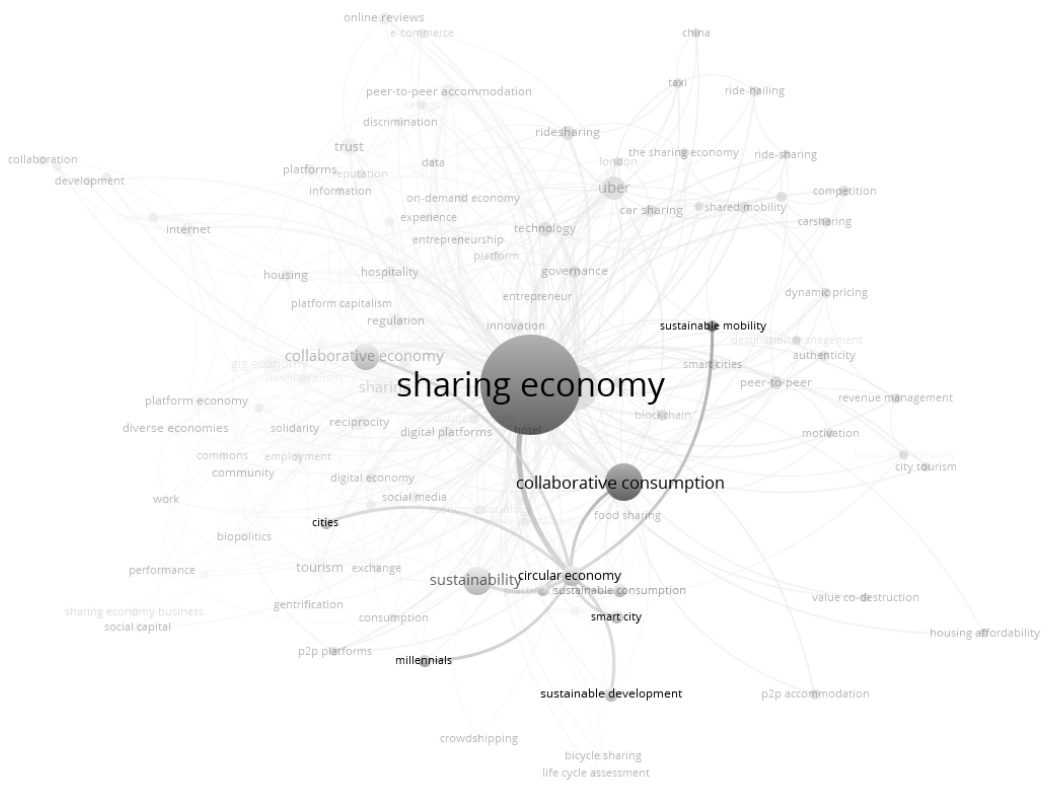

Source: Own preparation based on Scopus (2019). 
Scheme 4.

Sharing economy and collaborative economy co-occurrence

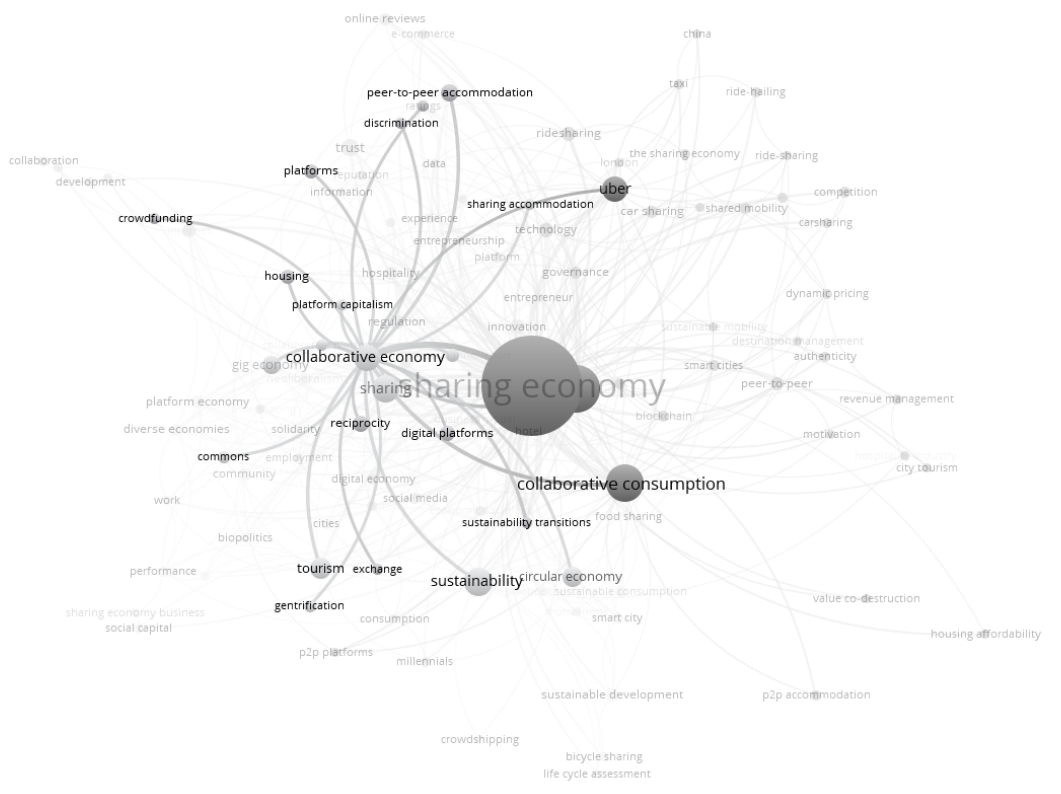

Source: Own preparation based on Scopus (2019). 
Scheme 5.

Sharing economy and gig economy co-occurrence

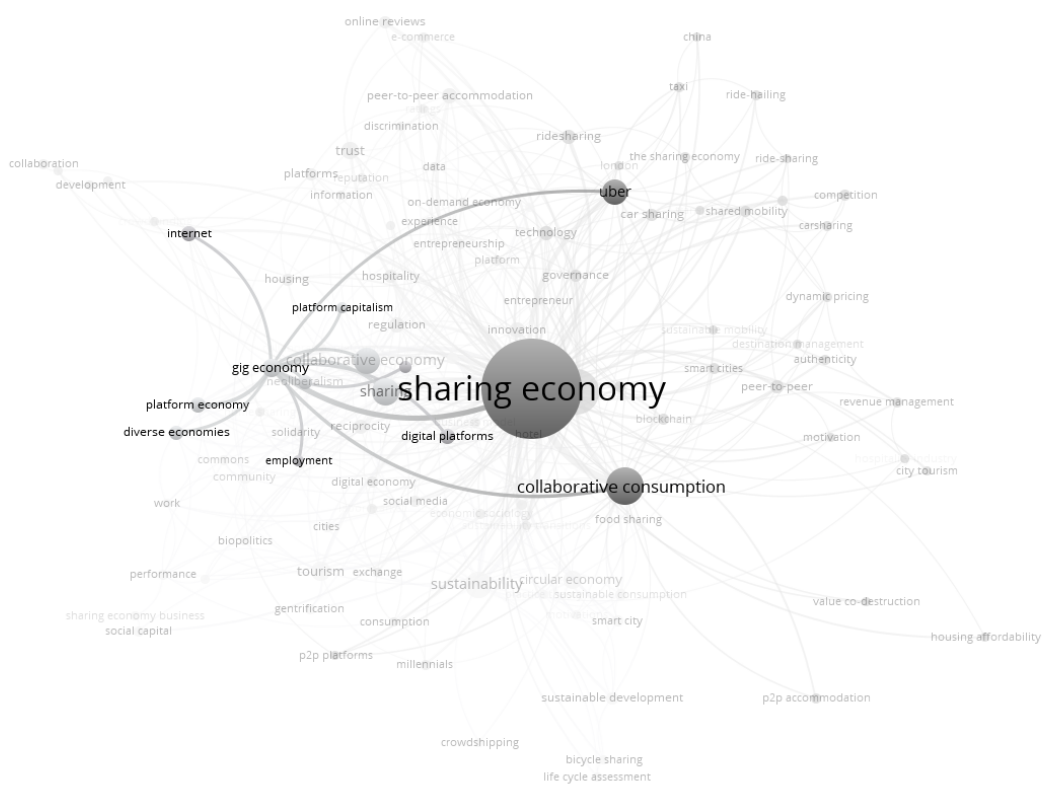

Source: Own preparation based on Scopus (2019). 
scheme 6 .

Sharing economy and platform economy co-occurrence

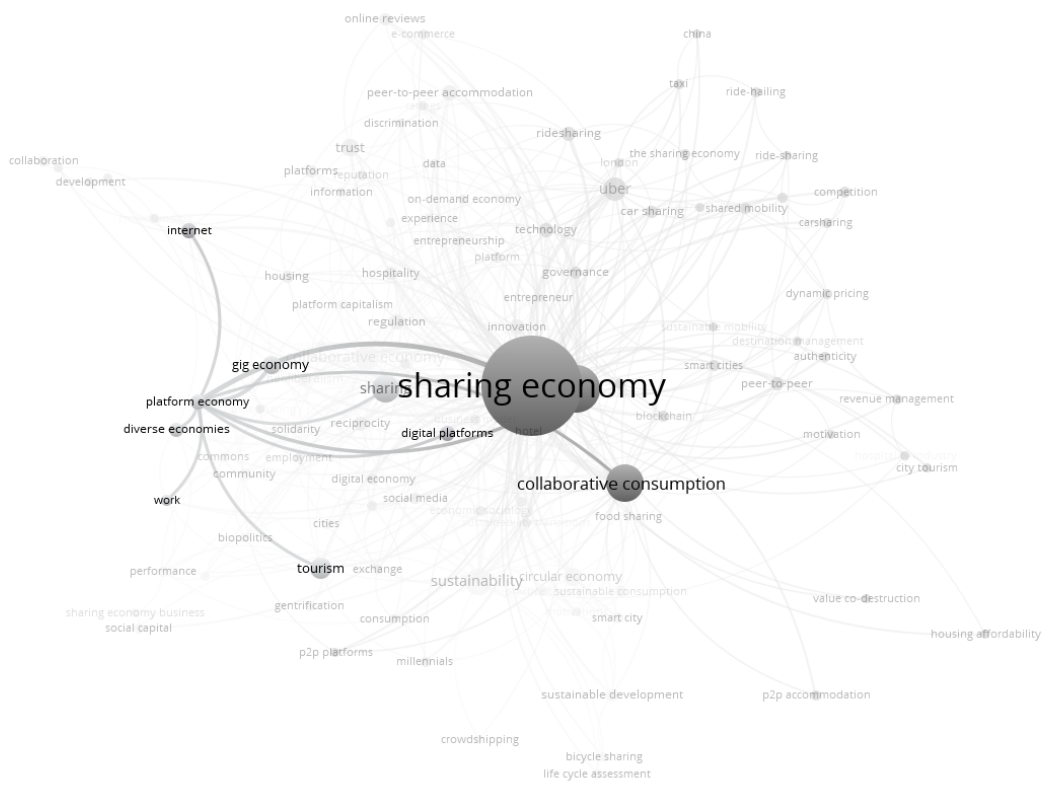

Source: Own preparation based on Scopus (2019). 